\title{
SOBRE UMA METODOLOGIA DE APRESENTAÇÃO DE IMAGEM MÉDICA*
}

\author{
Biancamano Pellegrinetti ${ }^{1}$, Luís Alberto Magna ${ }^{2}$
}

\begin{abstract}
Resumo Este trabalho demonstra os resultados preliminares, parciais, da experimentação e aceitação de uma metodologia para apresentação de imagens médicas, que utiliza programas simples, sem custo por serem "freewares", que podem ser utilizados em plataformas computacionais medianas, normalmente subutilizadas, não sendo necessários programas extensos, de alto custo, aprendizado dificultado pela sofisticação, tornando mais simples e acessível a possibilidade de visualização, apresentação, impressão, documentação, arquivamento, transmissão eletrônica e disponibilidade para consulta de uma gama de imagens médicas. Unitermos: Imagens médicas; Programas "freeware"; Ultra-som.
\end{abstract}

Abstract About a method for displaying medical images.

We present the preliminary results of testing and acceptance of a method for displaying medical images that employs simple computer freewares that can be run in unsophisticated computational platforms, which are commonly underutilized. This method allows easy and accessible visualization, printing, documenting, archiving, consulting and electronic transmission of a wide range of medical images without the need of expensive, complex and difficult to learn softwares.

Key words: Medical images; Freeware; Ultrasound.

\section{INTRODUÇÃO}

A documentação de imagens médicas, com o correr do tempo e conseqüente evolução tecnológica, conta com imensa variedade de possibilidades e técnicas, dependentes, principalmente, do processo envolvido na sua obtenção.

As soluções, porém, nem sempre são as mais adequadas à relação custo-benefício, conquanto necessitamos contemplar desde centros universitários, centros de pesquisa, serviços públicos, clínicas privadas, serviços particulares, convênios e, também, serviços que atendem gratuitamente.

Devemos, mais ainda, caracterizar e considerar a praticidade, qualidade, custo envolvido e, principalmente, procurar normas de padronização factíveis e também a fundamental aceitação dos métodos por parte dos médicos solicitantes.

Historicamente, começa-se com o denominado "radiology information system"

* Trabalho realizado no Departamento de Ecografia da Mater nidade de Campinas e Núcleo de Informática Biomédica da Universidade Estadual de Campinas (NIB-Unicamp), Campinas, SP.

1. Ultra-sonografista, Membro Titular do Colégio Brasileiro de Radiologia e Diagnóstico por Imagem (CBR).

2. Professor Titular do Departamento de Genética Médica da Unicamp, Vice-Coordenador do NIB-Unicamp.

Endereço para correspondência: Dr. Biancamano Pellegrinetti. Rua Coronel Quirino, 1169, $1^{\circ}$ andar, Cambuí. Campinas, SP, 13025-002. E-mail: biancamano@dgInet.com.br

Recebido para publicação em 7/7/2003. Aceito, após revisão, em 11/7/2003.
(RIS), evoluindo-se para os denominados "picture archives and communication systems" (PACS) e o mais recente "digital imaging and communications in medicine" (Dicom), e ainda uma quantidade de "softwares" proprietários, específicos ou gerais, de diversos desenvolvedores ${ }^{(1-3)}$.

No entanto, os sistemas, pacotes, programas, os "hardwares" e "softwares" complexos, ou ainda o alto custo de implantação, podem não satisfazer a necessidade de um usuário final, com capacidade, tendências e condições mais modestas, nem tornar prática a possibilidade de que o médico solicitante possa também trabalhar sobre estas imagens, mantê-las sob a forma de arquivos eletrônicos disponíveis, já que ele recebe apenas, usualmente, uma cópia em foto "Polaroid", foto brilhante, papel térmico, filme radiológico ou outro meio similar $^{(4)}$.

A disseminação dos recursos computacionais em nível pessoal, e a possibilidade de sua interligação em rede e por meio da "internet", apontam um caminho natural.

$\mathrm{O}$ grande fator que contribui, negativamente, para o uso dessas ferramentas, no entanto, é o custo a elas associado, uma vez que os equipamentos necessários (computadores e seus periféricos) e os programas que o colocam em funcionamento, os "softwares", atingiram um ritmo tão alto de mudanças e evolução que praticamente torna impossível a manutenção de sua atualização $^{(\mathbf{1}, \mathbf{4})}$.

A conseqüência desse fato é a subutilização e sucateamento de equipamentos já existentes, os quais, comumente, não mantêm capacidade de executar os programas mais atualizados, dados os requisitos mínimos para o adequado funcionamento impostos pelos novos "softwares".

Essa seqüência de eventos e o custo que os acompanha não devem, contudo, constituir a prática usual na utilização dos recursos da informática no plano pessoal. Ao contrário, os muitos equipamentos, já hoje subutilizados, podem voltar a desempenhar papel de relevância se alimentados com programas adequados e corretamente dimensionados.

Considerando somente o aspecto custo dos programas, este item já consome, hoje, mais da metade do custo final de uma configuração completa utilizável ("hardwaresoftware"), sendo essa uma das prováveis razões da disseminação, em todas as culturas, da utilização de cópias ilegais ou não autorizadas de programas computacionais comerciais $^{(2,4)}$.

Graças à popularização da "internet", no entanto, a disponibilização de programas de computador voltados à execução de determinadas tarefas, chamados, por isso mesmo, de aplicativos, ganhou dimensões antes nunca vistas. 
Esses programas têm algumas características que os tornam bastante atraentes, das quais uma das mais importantes é o fato de serem de tamanho reduzido, quando comparados aos programas congêneres ditos comerciais, e, como conseqüência, são pouco "vorazes", isto é, demandam recursos de "hardware" não exagerados, ocupam pouco espaço na memória permanente no disco rígido, requerem poucos recursos adicionais de memória volátil e, portanto, são capazes de serem executados com facilidade, numa gama grande de configurações de "hardware", incluindo aquelas que se encontram subutilizadas.

Um dos aspectos mais importantes associados a tais programas é o seu custo reduzido, ou mesmo ausente. Os programas disponibilizados por seus desenvolvedores na "internet" podem aparecer sob duas formas principais:

1. "Shareware": programa aplicativo cuja licença de uso é cobrada (a preços bem inferiores ao praticado pelos desenvolvedores de programas comerciais) e que estão disponíveis para uso, pelo usuário final, por prazo determinado ou apresentam algumas funcionalidades não ativadas até que o usuário final solicite sua licença e pague a respectiva taxa.

2. "Freeware": programa aplicativo cuja licença de uso e reprodução é livre de qualquer taxa, podendo ser utilizado livremente e instalado em quantos computadores o usuário final considere pertinente.

Objetiva este trabalho a demonstração de que, com a utilização de técnicas simples, rápidas, eficazes e de pouco dispêndio, pode-se trabalhar sobre imagens médicas, tornando-as passíveis de apresentação, impressão, documentação, arquivamento, transmissão eletrônica, disponibilidade para consulta, além de facilitar sua interpretação. O que se coloca neste trabalho são as conclusões decorrentes dos resultados parciais obtidos, focando-se, principalmente, a aceitação de um método voltado para esta finalidade, além de visar a uma maior discussão sobre o assunto.

\section{MATERIAIS E MÉTODOS}

Inicialmente, buscaram-se e "baixaramse" inúmeros programas de tratamento de imagem disponibilizados na "internet".
Cada um deles foi testado exaustivamente, em diversas plataformas computacionais, e os programas foram classificados, tendo sido escolhidos, entre dezenas deles, dois "freewares" para tratamento de imagens: um visualizador de imagens com alguns recursos de filtros e o outro, com recursos avançados, sendo estes, respectivamente, o IrfanView 32 bits versão 3.3, desenvolvido por Irfan Skiljan, Viena, Áustria, e o PhotoStudio versão 2.02SE da ArcSoft, Inc., EUA.

Essa escolha se deu em função da facilidade de instalação e manuseio desses programas, predicados com os quais os autores sentiram-se perfeitamente confortáveis para aplicá-los na prática diária, e a partir desta premissa supor que esta facilidade e com os preceitos de "freeware" pudessem atingir uma gama maior de adeptos ao seu uso, possibilitando que as imagens capturadas no momento do exame, digitalmente, assim fossem fornecidas ao solicitante do exame, e que usando os referidos programas a eles disponibilizados, pudessem visualizar, tratar, arquivar, imprimir, demonstrá-las aos pacientes, padronizando assim sua distribuição.

Em função da especialidade de um dos autores (ultra-sonografia), a avaliação se deu apenas neste campo de produção de imagem; contudo, seus atributos podem também, muito provavelmente, ser expandidos para outras metodologias de obtenção de imagens médicas.

Conquanto a aplicabilidade do método fosse testada pelos autores, inferiu-se que seria necessária uma experimentação "em campo", com a utilização da denominada versão beta do sistema, para que, dessa forma, os dados tabulados pudessem atestar a praticidade, confiabilidade, validade e, especialmente, a aceitação do método

Foram convidados, para testar os programas, profissionais médicos que constituíram duas amostras de populações: uma de usuários finais (ginecologistas e obstetras, já que as imagens utilizadas eram afeitas a estas especialidades) e outra de usuários de sistemas de imagens (médicos ultra-sonografistas).

Foram convidados 25 profissionais, cuja especialidade é ginecologia e obstetrícia, médicos que solicitam o exame ecográfico e recebem os laudos e documenta- ção na forma convencional, denominado grupo de solicitadores. Igualmente foram convidados dez profissionais que têm como especialidade, única ou secundária, a realização de exames ecográficos com emissão, por eles próprios, de laudos e documentação, na forma convencional, denominado de grupo de ecografistas.

Cada um deles foi abordado diretamente, pessoalmente ou por contato telefônico, para a anuência e interesse em participar do estudo, tendo havido aquiescência e estímulo por parte de todos os convidados, não tendo sido incluídos os médicos contatados que apresentaram desinteresse para tal, já que sua participação era voluntária.

Os endereços profissionais foram verificados e organizados e o material para avaliação foi enviado por meio postal e constou de carta de agradecimento, disquetes de computador com os programas, instruções para instalação e manuseio destes, e uma coletânea de imagens a serem testadas. Em cada caso foi enviado um questionário que deveria ser respondido com data limite específica, com tempo suficiente para avaliação da aplicabilidade e uso dos sistemas, além de outros dados gerais.

Na primeira semana após a postagem do material de avaliação foram já recebidos alguns questionários totalmente respondidos; ao todo foram recebidos nove questionários, seis do grupo de solicitadores e três do grupo de ecografistas.

Procedeu-se, então, a outro contato, com outro questionário, o qual continha perguntas específicas, buscando-se justificativa para tão baixo retorno de questionários e interesse despertados, consoante a inicial anuência e interesse em participar do estudo, tendo havido aquiescência e estímulo por parte de todos os convidados.

\section{RESULTADOS}

Os dados dos primeiro e segundo questionários são adiante apresentados.

Consideremos primeiramente os profissionais que avaliaram os programas e que referiram:

- A mídia de distribuição foi considerada adequada e prática em todos os questionários respondidos;

- as instruções para instalação foram consideradas claras em todos os questio- 
nários, suficientes em oito e insuficientes em um questionário;

- não houve problemas na instalação dos programas em oito questionários, um alegando falta de conhecimento em informática;

- não se notou nenhuma alteração na configuração original do computador utilizado na totalidade dos questionários;

- com relação ao espaço ocupado no disco rígido pelos programas, seis o referiram como pequeno e três não souberam avaliar;

- as instruções para utilização dos programas foram claras para a totalidade dos questionários, suficientes em oito e insuficientes em um caso;

- a interface dos programas foi considerada amigável e intuitiva em seis questionários, nem amigável nem intuitiva em um, e dois nada responderam;

- a avaliação sobre o grau de dificuldade no uso dos programas foi tomado como fácil em seis respostas, alguma dificuldade em duas e muito fácil em uma;

- o tempo médio de familiarização com os programas foi de uma hora;

- as imagens que acompanhavam os programas estavam em condições de serem visualizadas e tratadas em sete questionários, um respondeu poderem ser visualizadas mas não tratadas por falta de informação, e um, visualizadas, não respondendo se possíveis de serem tratadas;

- com o uso dos filtros as imagens melhoraram para sete participantes, não se alterando na opinião de dois;

- a acuidade diagnóstica com a utilização dos filtros, comparativamente, melhorou em cinco respostas e não se alterou em quatro.

Consideremos agora as razões referidas para não utilizarem os programas, não res- ponderem ao questionário primário, mesmo tendo aceito participar do estudo:

- Acusaram não terem recebido o material para avaliação dois participantes, e um refere não se lembrar de tê-lo recebido;

- seis participantes, tendo recebido o material para avaliação, não o utilizaram por diversos motivos, alegando falta de tempo, não habituados com a utilização do computador, e alguns não mais puderam ser contatados;

- a idade média dos participantes foi de 46 anos;

- o tempo médio de formatura, graduação em medicina, foi de 20 anos;

- dos participantes referentes ao uso de computador, $12 \%$ referiram não o usar, usam-no eventualmente $44 \%$ e usam-no sempre outros $44 \%$ dos médicos-alvo;

- em relação a conhecimentos de informática, $67 \%$ dos participantes referem que são poucos, conhecimentos médios são referidos por $33 \%$ e nenhum deles refere conhecimentos avançados em informática;

- perguntados sobre a possibilidade de usar programas como os pesquisados na prática diária, a resposta, para $16 \%$ dos pesquisados, foi que não viam nenhuma possibilidade, possibilidade pequena foi a resposta de $27 \%$, possibilidade mediana em $11 \%$ e possibilidade grande em $44 \%$.

\section{DISCUSSÃO}

Os resultados parciais obtidos mostram, primariamente, que mesmo com interesse manifesto na aplicabilidade do método, este não foi utilizado na forma da expectativa dos autores, o que se torna, naturalmente, um estímulo para a sua discussão e reordenamento de premissas, posição que decorre do baixo retorno na participação voluntariamente aceita ( 9 de 25 , ou $36 \%$ ).

\section{CONCLUSÃO}

Os dados obtidos, embora parciais e não passíveis de, no momento, serem submetidos a análise estatística, servem como ponto de reparo, demandando várias questões:

1. Seria a expectativa dos autores, certos de que o método é de extrema valia para a prática diária, em função do aproveitamento de sistemas computacionais comumente encontrados e subutilizados, inexistente custo de implantação, manejo fácil e eficiente, frustrada em função de quais variáveis (da idade, tempo de formado, conhecimentos em informática, interesse no assunto, etc.)?

2. Se o público alvo fosse diverso, no qual a informática já tivesse se arraigado como prática diária, necessária e dela dependente, os resultados seriam diversos?

De tudo que os resultados preliminares permitem concluir, o mais provável é que ainda existe uma natural resistência à utilização da informática, na prática médica diária do diagnóstico por imagem, tanto por parte dos médicos ultra-sonografistas quanto dos usuários, ou solicitadores de exames, restringindo sua aplicação à manipulação de cadastro de pacientes e emissão de textos de laudos, o que configura uma subutilização de sistemas computacionais, já que estes podem contribuir positivamente na melhoria do resultado final desses procedimentos.

\section{REFERÊNCIAS}

1. Gondo M. Esse investimento compensa? Jornal da Imagem, março 2002:33.

2. Arquivos digitais em radiologia. (I) Sistemas digitais em diagnóstico por imagem. Originariamente em http://www.radiology.com.br/pacs.htm

3. The Dicom standard. Disponível em: http://www. psychology.nottingham.ac.uk.staff/cr1/dicom.html.

4. Dissertação de mestrado. http://infonib.nib. unicamp.br/ biancamano/ 